\title{
Efeito da utilização da enzima alfa-amilase em tratamento de efluente de arroz parboilizado com Saccharomyces boulardii
}

\author{
G. L. FERREIRA ${ }^{1}$, D. G. SANTOS ${ }^{1}$, F. MANZOLLI ${ }^{1}$, G. R. L. MENDES ${ }^{2}$ e P. J. S. FILHO ${ }^{1}$ \\ ${ }^{1}$ Instituto Federal Sul Rio-Grandense, curso de Engenharia Química \\ ${ }^{2}$ Universidade Federal de Pelotas, Programa de Pós-Graduação em Biotecnologia \\ E-mail para contato: grazilemos95@gmail.com
}

RESUMO - A maior geração de efluente no processo de parboilização do arroz ocorre devido ao tratamento térmico realizado, ocasionando a transferência de compostos orgânicos, fósforo e nitrogênio, entre outros que podem ser metabolizados pela levedura Saccharomyces boularddi. Avaliamos a ação da enzima alfa-amilase no efluente de arroz parboilizado através do crescimento da levedura $S$. boularddi. Para tal, realizou-se um tratamento prévio no efluente com concentração de 20 ppm da enzima por 30 minutos. Nas amostras previamente tratadas, e em um padrão comparativo, se adicionou o inóculo da levedura e se efetuou um cultivo de 30 horas em um banho-maria com agitação à $28^{\circ} \mathrm{C}$, coletando-se amostras durante o cultivo e obtendo-se a resposta em UFC médio (Unidades Formadoras de Colônia). O prétratamento realizado apresentou melhores resultados no crescimento da levedura em relação ao padrão, indicando que houve desdobramento de substratos em compostos com maior facilidade de serem metabolizados pela levedura. O pré-tratamento quando comparado com o padrão teve diferença estatística significativa para $\alpha<0,5$. Dessa forma, pode-se concluir que o efeito da ação da alfa-amilase sugere a existência de substrato passíveis de sua ação e que estes foram disponibilizados para o consumo da Saccharomyces boulardii, garantido um melhor crescimento desta.

\section{INTRODUÇÃO}

A busca por tratamentos de efluentes que visam minimizar os impactos ambientais causados pelas atividades industriais é um esforço necessário e que deve ser aprimorado. Uma das formas de tratamento que vem sendo utilizadas é o processo de biorremediação, que consiste da degradação de compostos tidos como contaminantes por microorganismos, através de reações enzimáticas, resultando em substratos acessíveis para a absorção e incorporação no metabolismo microbiano, ou conversão destes poluentes em produtos menos tóxicos ou compostos de interesse. No tratamento de águas residuárias agroindustriais, inúmeros estudos já foram descritos utilizando bactérias, fungos, algas e leveduras como agentes de degradação de poluentes.

A escolha da espécie a ser utilizada depende do tipo de contaminante presente na água residuária, visto que a maquinaria metabólica e as enzimas produzidas são distintas entre os microorganismos. Contudo, em alguns casos os compostos presentes em efluentes, não estão completamente biodisponíveis para que os microorganismos a serem utilizados possam assimila-los completamente, neste caso, torna-se necessário a realização de um tratamento prévio.

Esse tratamento pode ser realizado por enzimas que possuem os sítios de ação específicos para esses compostos, os transformando-os em fontes mais acessíveis, como no caso da 
enzima celulase utilizada como tratamento prévio ao da oxidação aeróbica (Sangave e Pandit, 2006). Enzimas podem ser usadas para auxiliar a degradação de efluentes de milho (Zamora, et al., 2015), de efluentes líquidos (Kües, 2015), entre outros, demonstrando a capacidade de se usar enzimas previamente aos processos de tratamento de efluentes.

A produção do arroz parboilizado caracteriza-se pela presença de um processo de encharcamento, gerando altos volumes de efluente com altos índices de demanda química de oxigênio (DQO) (5000 a $7000 \mathrm{mg}$ de $\left.\mathrm{O}_{2} / \mathrm{L}\right)$, além do nitrogênio amoniacal e orgânico, fosfatos e outros. A descrição clara da composição desse efluente ainda não foi elucidada, havendo publicações demonstrando a variação dos valores de DQO, os diferentes componentes do ciclo do nitrogênio, sólidos suspensos totais, fósforo e ácidos voláteis totais (Queiroz e Koetz, 1997). Assim sendo, não há uma caracterização efetivamente dos componentes existentes, não permitindo direcionar a seleção dos micro-organismos que melhor poderiam utilizar essas fontes em suas rotas metabólicas de desenvolvimento.

Contudo, estudos recentes demonstraram a possibilidade de cultivo das leveduras Pichia pastoris (Gil de los Santos et al., 2012) e Saccharomyces boulardii (Gaboardi, 2015) no efluente de arroz parboilizado obtendo-se bons resultados de remoção e absorção do fósforo presente. Nos dois casos, tornou-se necessário efetuar-se a adição de uma fonte complementar de carbono, pois, mesmo o efluente possuindo altos índices de DQO, sugerindo altos teores de fontes de carbono, essas leveduras não conseguem assimilar as mesmas.

Suribabu et al. (2014) demonstraram que a cepa Brevibacillus borostelensis R1 produz alfa amilase quando cultivado no efluente de arroz parboilizado, sugerindo a disponibilidade desse tipo de fonte de carbono no efluente. Dessa forma, neste estudo buscou-se avaliar a influência no crescimento celular da levedura $S$. boulardii no efluente previamente tratado com a enzima alfa-amilase sem adição de nenhuma fonte extra de carbono.

\section{MATERIAIS E MÉTODOS}

\subsection{Micro-organismo}

S. boulardii foi obtida de uma cápsula de Floratil ${ }^{\circledR}$, pela reativação do liofilizado, cultivado em $10 \mathrm{~mL}$ de meio YM por $24 \mathrm{~h}$ a $150 \mathrm{rpm}$ e $28^{\circ} \mathrm{C}$. Após o cultivo, foi realizada a semeadura de uma gota da cultura em placas de YM sólido, e incubação por $48 \mathrm{~h}$ em estufa a $28{ }^{\circ} \mathrm{C}$, para crescimento e isolamento das colônias. As placas foram mantidas sob refrigeração a $4{ }^{\circ} \mathrm{C}$ e repicadas a cada 15 dias.

\subsection{Cultivo da Levedura}

\section{Tratamento prévio}

No pré-tratamento foi utilizado a enzima alfa-amilase do laboratório AG XXL (ação enzimática numa faixa de $15-55^{\circ} \mathrm{C}$ e $\mathrm{pH}$ de 4,5 ). Sendo utilizada uma concentração de 20 ppm em efluente com pH 4,5 e com tempo de ação de 30 minutos em banho-maria.

\section{Cultivo da levedura em banho-maria com agitação}

Os pré-inóculos e o inóculo de $S$. boulardii foram produzidos em meio YM (Yeast Medium, Difco, USA) em agitador orbital a $150 \mathrm{rpm}, 28^{\circ} \mathrm{C}$ por 12 horas. Os cultivos foram efetuados a $28{ }^{\circ} \mathrm{C}$ por 30 horas, usando $20 \mathrm{~mL}$ do efluente pré-tratado em balões aletados de $100 \mathrm{~mL}$ e adição de $10 \%$ em volume do inóculo. Um cultivo padrão da levedura no efluente de arroz parboilizado sem o tratamento prévio com a enzima foi realizado. Três cultivos 
foram efetuados no efluente previamente tratado com enzima e um como padrão de referência.

A viabilidade celular foi determinada as $0 \mathrm{~h}, 3 \mathrm{~h}, 9 \mathrm{~h}, 12 \mathrm{~h}, 15 \mathrm{~h}$ e $30 \mathrm{~h}$ de cultivo, por contagem de unidades formadoras de colônias (UFC. $\mathrm{mL}^{-1}$ ) usando placas de YM sólido a $28^{\circ} \mathrm{C}$.

\subsection{Análise estatística}

$\mathrm{Na}$ análise estatística usou-se o software Statistic versão 7. Os dados foram analisados por ANOVA (análise de variância) avaliando-se a influência dos fatores tempo, concentração e sua interação e a diferença de médias avaliadas pelo teste de Turkey $(\alpha<0,05)$, sendo a normalidade testada por Shapiro-Wilk.

\section{RESULTADOS E DISCUSSÃO}

Na Tabela 1 encontram-se os valores de UFC.ml ${ }^{-1}$ dos três cultivos efetuados no efluente previamente tratado com a enzima alfa-amilase e sem tratamento prévio (denominado de padrão).

Tabela1 - Contagem (média e desvio-padrão) de UFC da levedura $S$. boulardii nos cultivos com a ação prévia da enzima alfa-amilase (Cultivo 1,2 e 3 ) e o no cultivo padrão ao longo de 30 horas de cultivo.

\begin{tabular}{|c|c|c|c|c|}
\hline $\begin{array}{l}\text { Tempo de } \\
\text { Cultivo }\end{array}$ & $\begin{array}{c}\text { Cultivo } 1 \\
\left(\mathrm{UFC} \cdot \mathrm{ml}^{-1} \times 10^{5}\right)\end{array}$ & $\begin{array}{c}\text { Cultivo } 2 \\
\left(\mathrm{UFC} \cdot \mathrm{ml}^{-1} \times 10^{5}\right)\end{array}$ & $\begin{array}{c}\text { Cultivo } 3 \\
\left(\mathrm{UFC} \cdot \mathrm{ml}^{-1} \times 10^{5}\right)\end{array}$ & $\begin{array}{c}\text { Padrão } \\
\left(\text { UFC.ml } l^{-1} \times 10^{5}\right)\end{array}$ \\
\hline $0 \mathrm{~h}$ & $8,60 \pm 2,12^{\mathrm{a}}$ & $4,50 \pm 0,58^{\mathrm{a}}$ & $8,63 \pm 2,28^{\mathrm{a}}$ & $5,70 \pm 0,75^{\mathrm{a}}$ \\
\hline $3 \mathrm{~h}$ & $8,65 \pm 1,34^{b}$ & $6,37 \pm 0,32^{\mathrm{c}}$ & $4,35 \pm 0,21^{\mathrm{d}}$ & $7,53 \pm 0,45^{\mathrm{b}}$ \\
\hline $9 \mathrm{~h}$ & $81,33 \pm 3,21^{\mathrm{e}}$ & $42,67 \pm 6,43^{\mathrm{f}}$ & $84,00 \pm 14,42^{\mathrm{e}}$ & $105,50 \pm 3,53^{\mathrm{g}}$ \\
\hline $12 \mathrm{~h}$ & $148,33 \pm 27,42^{\mathrm{h}}$ & $110,00 \pm 10^{\mathrm{h}}$ & $60,00 \pm 2^{\mathrm{i}}$ & $26,67 \pm 6,11^{\mathrm{i}}$ \\
\hline $15 \mathrm{~h}$ & $84,50 \pm 4,94^{\mathrm{j}}$ & $90,00 \pm 0^{\mathrm{j}}$ & $93,33 \pm 7,63^{j}$ & $52,50 \pm 4,95^{\mathrm{k}}$ \\
\hline $30 \mathrm{~h}$ & $102,33 \pm 4,04^{1}$ & $93,50 \pm 13,4^{1}$ & $101,50 \pm 10^{\mathrm{m}}$ & $29,67 \pm 0,58^{\mathrm{n}}$ \\
\hline
\end{tabular}

* as letras representam diferença estatística entre os tratamentos no mesmo tempo de cultivo para $\alpha<0,5$ (teste de normalidade por Shapiro Wilk e teste de comparação de médias por Turkey).

Os resultados apresentados na Tabela 1 foram plotados em um gráfico em que pode ser observado o crescimento da levedura S. boulardii ao longo do tempo de cultivo, como mostrado na Figura 1. 
Figura 1 - Curva de crescimento da levedura S. boulardii ao longo do cultivo com respectivos desvios padrões em cada ponto.

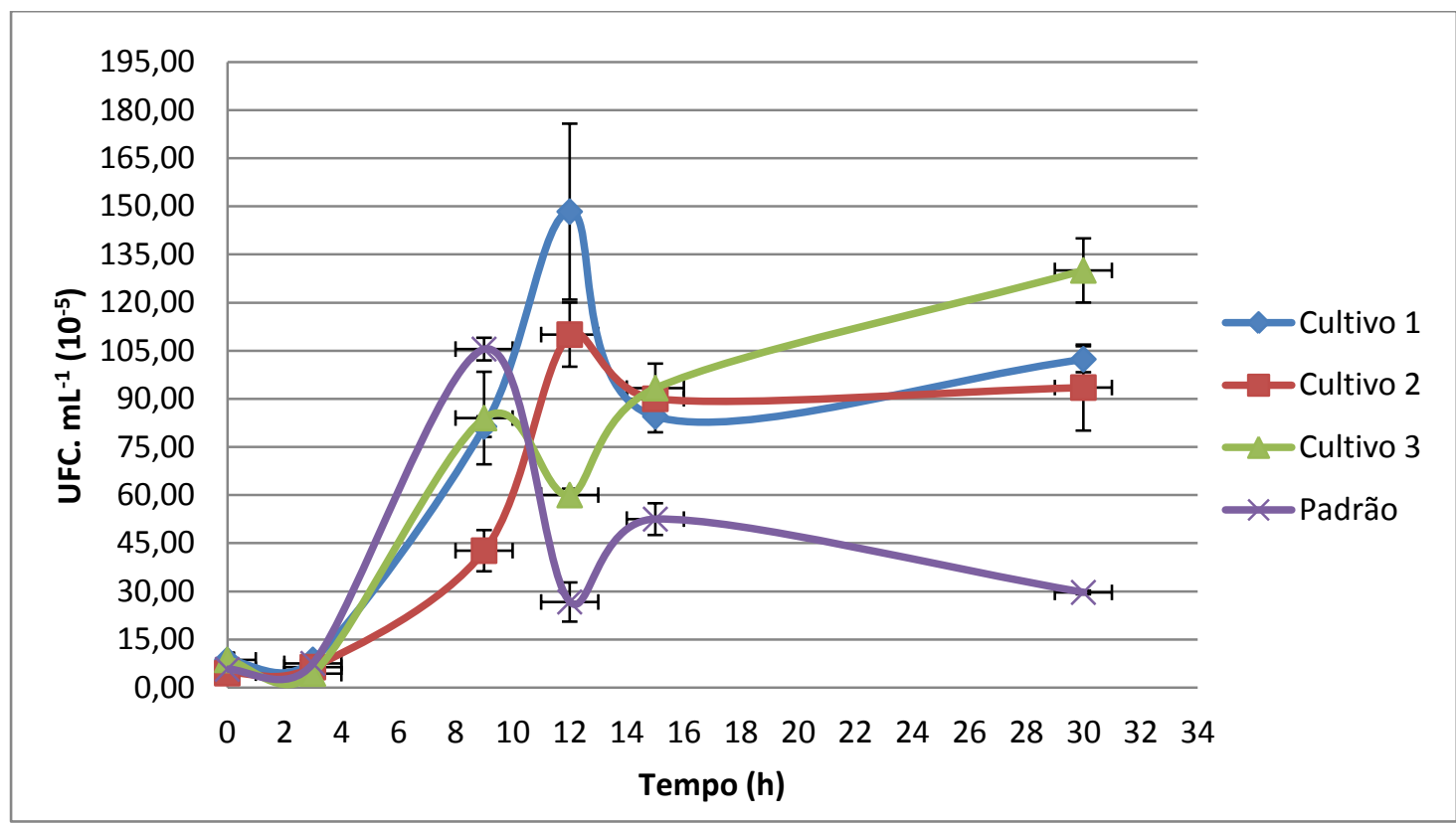

A enzima alfa- amilase caracteriza-se por efetuar a catalise em substratos como glicogênio, amilose e amilopectina, efetuando a hidrólise das ligações a-1, 4 da amilose, amilopectina e glicogênio, liberando maltose e isomaltose (MOTTA,2003). A maltose e a isomaltose são dissacarídeos formados por glicose, fonte energética passível de utilização para o crescimento da levedura $S$. boulardii., Santos et al. (2013) relatam que a maltose e a sacarose são as principais fontes de carbono utilizadas em processos industriais para se obter um ambiente ótimo para o crescimento da levedura $S$. boulardii .

Como pode ser observado,através da Tabela 1 no tempo $0 \mathrm{~h}$ não houve diferença estatística entre os cultivos e o padrão, resultado esperado em função de ter sido utilizado o mesmo inóculo para todos. Em $12 \mathrm{~h}$ o cultivo padrão e o Cultivo 3 obtiveram comportamento semelhante, ambos com queda no crescimento significativa. Nas respostas obtidas em $9 \mathrm{~h}, 15$ $\mathrm{h}$ e $30 \mathrm{~h}$ a concentração da levedura no cultivo Padrão apresentou diferença significativa em relação aos três cultivos realizados, sendo em $15 \mathrm{~h}$ não houve diferença na concentração celular entre os Cultivos 1, 2 e 3 . Além disso, verifica-se que a partir das $9 \mathrm{~h}$ o Padrão começa a ter uma queda no crescimento da levedura $S$. boulardii.

Em estudos anteriores (Gaboardi,2015), verificou-se que cultivos realizados em agitador horizontal com adição de $1 \%$ de sacacore os resultados de crescimento obtidos foram de $3 \times 10^{7}$ até $1,8 \times 10^{8}$ para $12 \mathrm{~h}$, enquanto o Cultivo 1 com adição de enzima foi de $8 \times 10^{5}$ até $1,4 \times 10^{7}$ e o Cultivo 2 de $4,5 \times 10^{5}$ até $1,1 \times 10^{7}$, apresentando assim,dois log de crescimento em relação ao obtido com fontes extras de carbono. O mesmo ocorre para o dados obtidos pelo mesmo estudo em cultivos realizado em YM que teve a mesma faixa de crescimento ao de adição de sacarose. Além, Gaboardi (2015) teve um decaimento de crescimento no efluente 
bruto (sem adição de fontes extras de carbono) a partir das $9 \mathrm{~h}$, semelhante ao resultado obtido nesse estudo.

Apesar do custo de aquisição de enzimas serem normalmente elevados, a utilização de uma concentração próxima de $20 \mathrm{ppm}$ pode ser vantajosa, frente ao fato de que não seria necessário a adição de fontes extras de carbono que aumento o nível de DQO, além de com a sua utilização teve-se um crescimento da levedura ao longo do cultivo bastante significativo.

\section{CONCLUSÃO}

Através dos dados obtidos na realização dos cultivos verificou-se um melhor crescimento da levedura Saccharomyces boulardii nos efluentes que obtiveram o tratamento prévio realizado com a enzima alfa-amilase sugerindo a presença de glicogênio, amilose e amilopectina.

\section{REFERÊNCIAS}

Gaboardi, G , "Produção do probiótico Saccharomyces boulardii em efluente de arroz parboilizado e avaliação da biorremediação". 63f. - Dissertação (Mestrado). Programa de Pós-Graduação em Biotecnologia. Universidade Federal de Pelotas. Centro de Desenvolvimento Tecnológico. Pelotas, 2015.

García-Zamora, J.L., Sánchez-González,M., LozanoJ.A.Jáuregui,J., Zayas T,Santacruz, V.,Hernández, F.,Torres, E.. Enzymatic treatment of wastewater from the corn tortilla industryusing chitosan as an adsorbent reduces the chemical oxygen demandand ferulic acid content. Process Biochemistry, 50, 125-133, 2015. doi:10.1016/j.procbio.2014.10.012

Gil de los Santos, D., Gil-Turnes, C., Conceição, F.R.,, Bioremediation of parboiled rice effluent supplemented with biodiesel-derived glycerol using Pichia pastoris X-33. TheScientificWorldJournal. 2012 doi:10.1100/2012/492925

Kües, U. Fungal enzymes for environmental management. Current Opinion in Biotechnology 33:268-278, 2015. doi:10.1016/j.copbio.2015.03.006

Queiroz, M., Koetz, P.R., Caracterização do efluente da parboilização do arroz. Revista Brasileira de Agrociência. 3, 139-143, 1997.

Sangave, P.C. e Pandit, A.B. Enhancement in biodegradability of distillery wastewater using enzymatic pretreatment J. Environ. Manage., 78,. 77-85, 2006.

Santos, E., Schautz, L., Cardoso, C., Ernandes, J., Baristote, M. The effect of the structural complexity of the carbon and nitrogen source in the fermentative performance of industrial yeast. doi: $10.5902 / 2179-460 \times 651$.

Suribabu, K, Govardhan, T.L. e HemalathaK.P.J. Application of partially purified -amylase produced by Brevibacillus borostelensis R1 on sewage and effluents of Industries, Int.J.Curr.Microbiol.App.Sci , 3(7), 691-697,2014. 
Valter T. Motta. Bioquímica Clínica: Princípios e Interpretações. Enzimas, $4^{\circ}$ ed. Porto Alegre: editora, médica Missau-São Paulo: Robe Editoral, EDUCS- Caxias do Sul, 2003. 